\title{
Minhas histórias, minhas memórias
}

\author{
Maioque Rodrigues Figueiredo ${ }^{1}$
}

DOI: http://dx.doi.org/10.20435/tellus.v17i33.452

Sou Terena, os ditos excluídos da sociedade, os subalternos, colonizados, oprimidos. Pois nesse caminho conturbado, ainda não concluído, mas posso dizer que não sou mais a mesma pessoa, sou outra, em uma palavra resumo tudo o que estou sentindo, me sinto libertado. Essa narrativa é construída a partir daquilo que me tornei, daquilo que consigo enxergar, onde estou situado, de onde falo.

Sou parte da construção dos sonhos desse povo, que por séculos foram submetidos à imposição colonial ocidental, é a partir desse entendimento que é o meu ponto de partida. Undy (que na língua Terena pronome primeira pessoa do singular "eu") Maioque Rodrigues Figueiredo, undy kopenoty (índio) Terenoé.

Nasci em Campo Grande, capital de Mato Grosso do Sul. Segundo a minha mãe tive complicações no meu nascimento no momento do parto, pois algumas irmãs que ali trabalhavam naquele hospital, acharam por bem me batizar, o batismo poderia me curar naquele momento e me deram o nome de José Maioque, porém ao registrar em cartório o primeiro nome não foi registrado. As pessoas de mais idade da aldeia me chamam de Zé ou Zé Maioque inclusive os meus irmãos, os amigos que fui construindo me chamam de Maioque.

Nasci dentro de uma família tradicional Terena na Terra indígena Buriti, município de Dois Irmãos do Buriti em Mato Grosso do Sul (MS), meus avós paternos e avós maternos falavam a língua Terena e seguiam a risca os costumes e tradição Terena. Os Terenas são remanescentes do povo Aruák.

Lembro que minha avó Flavia Alcântara, mãe de meu pai Joaquim Loureiro Figueiredo Neto, lembrava das histórias do Exivá, eu construía esse lugar na minha imaginação. Segundo minha avó era um lugar com muita "fartura", tinha muita caça, pesca, mel, tinha muita roça, a mãe dela tinha vindo de lá do Exivá. Minha avó era uma excelente tecelã, fabricava: coxas, mantas, redes de algodão e lã. Às vezes ficava

${ }^{1}$ Universidade Católica Dom Bosco (UCDB), Campo Grande, Mato Grosso do Sul, Brasil. 
o dia todo com ela tecendo lã, tinha uma peça que ela mesma fabricava chamado "cambito", esse servia para fabricar os fios de lã ou de algodão. A lã era fixada ou amarrada na base do cambito, outro fazia o movimento de girar o cambito no caso eu e meus primos, a minha avó ia conduzindo e firmando a lã, os fios iam sendo fabricados e ficavam cada vez mais compridos, enrolávamos os fios na base do cambito, às vezes ficava bem pesado. O trabalho dos meninos era girar o cambito, para as meninas ficava o preparo das lãs. Lembro também que ela fabricava pote de barro, esse servia para armazenar água, lembro do cheiro gostoso da água, tudo era tudo muito natural.

Meu avô João Batista Figueiredo, pai de meu pai era uma pessoa extraordinária, falava pouco o português, foi Capitão (termo usado para definir a representação política da aldeia indígena) na aldeia Buriti, era um koéxomoneti (Terena que adquiriu experiências ao longo da vida e, domina os fenômenos da vida, da natureza e da espiritualidade), ou "pajé" líder espiritual muito conhecido e respeitado na região, pois dominava os conhecimentos místicos, espirituais e da natureza. Conheci e convivi com meu avô, presenciei muitos trabalhos realizado por ele, esta narrativa foi construído em diálogo com meu tio Sebastião Figueiredo e meu pai Joaquim Loureiro Figueiredo Neto, ambos são irmãos filho de João Batista Figueiredo.

Era muito constante a presença de pessoas de todos os lugares da região, inclusive pessoas de outros estados vinham em busca de resolver seus problemas de saúde, muitas vezes desenganados pelos médicos. Lembro de alguns rituais feito por ele como o canto com o porunga feito de cabaça onde passava horas cantando, parecia estar dialogando com alguém que só ele enxergava, esse parecia estar trazendo alguma mensagem espiritual do paciente, se a alma dele estava longe ou perto, se a alma estivesse perto o ritual era menos longo, se a alma estivesse longe o ritual seria mais longo era preciso mais canto para trazer a alma de volta

Outro ritual era chamado de "Benzer" ou "dar passo", semelhante a uma oração, com uma voz bem suave e piano, esse ritual era constante mesmo que as pessoas não tivesse nenhum tipo de doença, ou também para crianças com quebrante, ou criança que choram muito a noite, o ritual também era feito contra picada de cobra, dor de dente, dor de cabeça. O ritual das ervas medicinais, João Figueiredo conhecia muito o poder das ervas, coletava e fazia chá para vários tipos de doenças.

Outros conhecimentos tradicionais que dominava era sobre os fenômenos da natureza, nas rodas de conversar ele dizia que tudo na natureza tem dono, a mata 
tem dono, a água tem dono, os animais tem dono, e cada um desses tem a sua importância para a natureza e para as pessoas, meu avô dizia que a natureza conversa com a gente, se entendermos ela, ela nos tramite muitas informações, como por exemplo: o canto dos pássaros, o vento, a lua o sol pode agir sobre nós. Para extrair matéria prima da mata é preciso respeitar a fase da lua.

A imagem abaixo foi desenhada por um artista popular da Aldeia Nova Tereré retrata um pajé Terena conforme descrevemos acima e foi desenhado pelo professor Marquinhos Basílio, natural da aldeia Bananal PIN Taunay, município de Aquidauana, MS, hoje reside e Sidrolândia e é professor da Escola Cacique João Batista Figueiredo.

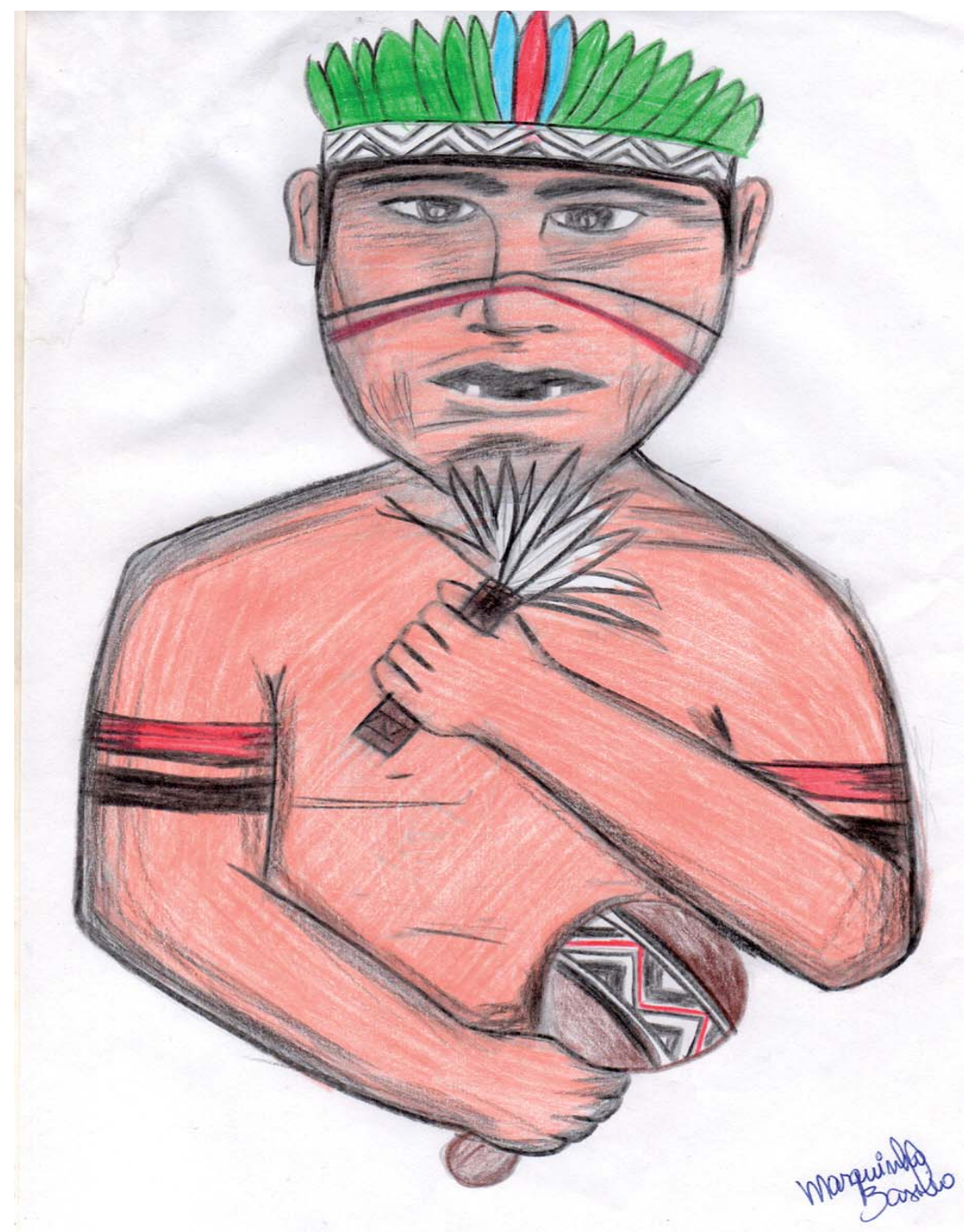


Meu avô João Batista Figueiredo, koéxomonéti um Terena autêntico que ao longo da vida soube compreender a arte de viver, Terena que adquiriu experiências ao longo da vida e, dominou os fenômenos da vida, da natureza e da espiritualidade.

Meu avô João Batista Figueiredo contava muitas histórias do cotidiano, da sua experiência como capitão e dos trabalhos realizados como pajé. Os conhecimentos tradicionais as sabedorias e conselhos dele como capitão e pajé era lei para as famílias Terena, as pessoas que conviveram com ele na época seguiam à risca os conselhos que ele falava principalmente a questão relacionada à crença e a cosmovisão indígena.

A convivência com meus avôs maternos foi pouco, mas lembro das histórias do cotidiano dos meus avôs, minha avó Antonia e meu avô Silvério, pais de minha mãe Rozinha Mamedes Rodrigues Figueiredo, eles relatavam muitos sobre os trabalhos nas fazendas nas proximidades da Terra Buriti.

Meus avós maternos tinham nove filhos, oito homens e uma mulher, todos criados na roça, plantavam de tudo naquela época, arroz, feijão, mandioca, criavam muita galinha, porco; lembro também que tinha muito peixe no córrego Buriti. Hoje os filhos dos meus avôs muitos estão na aldeia urbana na Aldeia Tereré, a maioria trabalha nas empresas. A minha mãe única mulher entre oito irmãos homens, segunda mais velha ela tinha que dar conta de cuidar de todos os irmãos mais novos, que eram muitos. Segundo relatos de minha mãe, ela lavava roupa na beira do córrego Buriti, que passava bem perto da Aldeia Barreirinho, ao mesmo tempo em que lavava roupa, também nadava e pescava, até hoje os meus tios ganham o apelido de lambari, porque dizem que nadavam igual peixe.

A minha mãe é um exemplo de pessoa, um exemplo de companheira e amiga, pois ela estava presente em todos os momentos de nossa vida familiar. Com ela, mesmo longe de nosso povo, ela nos contava as história dos Terena, mamãe também era falante da língua Terena. Deixo aqui todo meu carinho e respeito pela minha querida Mãe que partiu feliz, pois ela queria ver seus filhos formados. Mamãe estava entre a vida e a morte no hospital, quando estava marcada a entrevista do processo seletivo de mestrado na Universidade Federal em Campo Grande, priorizei estar junto de minha mãe, porque nunca mais iria vê-la.

Ainda pequeno, ali aos três, quatro anos de idade, fui morar na Aldeia Porto Lindo povo Guarani, município de Japorã, MS. Ali cresci até a idade de ir para escola, minha infância foi no meio do povo Guarani, onde aprendi a falar um pouco a língua Guarani. Lembro que fui criança pra valer, brinquei muito, fui muito feliz na minha 
infância. Meu pai era enfermeiro da Fundação Nacional do Índio (FUNAI), ele concluiu o quarto ano dos anos iniciais, ele é muito inteligente, é falante da língua Terena e aprendeu também falar a língua Guarani. Como enfermeiro da FUNAI, não deixou faltar nada pra mim e minha família.

A minha vida na Aldeia Porto Lindo está guardado na memória cada momento, fui muito feliz ali naquela aldeia, brinquei, nadei, passeava a aldeia toda, lembro que tinha muitos rios, cachoeiras, matas, muitas árvores frutíferas. Eu gostava de colher frutos na mata como a jabuticaba, era nativo ali naquele lugar, armava arapuca, jogava bola, tenho saudade e ainda quero retornar para rever os amigos que ali construí.

Aos sete anos de idade entrei na escola, lembro que chamava a nossa escola de "missão", a escola ficava em uma chácara, com muitas plantações, árvores frutíferas, tinha também igreja, naquela época a escola ficava fora da aldeia, lembro que íamos de charrete às vezes íamos a pé.

Lembro que foi um desastre a escola na minha vida, estava perdido, não entendia o que a professora falava, parece que queriam me alfabetizar na marra, eu não conseguia ler, lembro que ate ficava de castigo, porque a professora explicava, e quando chegava a minha hora de ler não saia nada. Meu pai ficava sabendo, já me dava uns puxões de orelha, tabuada nem se fala, meu Deus, como era difícil, e assim foi o primeiro e o segundo ano na escola. Nesses meios lembro que viajava para visitar meus avos maternos e paternos nas férias na aldeia Buriti.

Meu pai foi transferido para aldeia Cachoeirinha município de Miranda, MS, outra escola, todos os alunos falavam a língua Terena, não entendia nada, nem na escola nem fora da escola, os professores lembro que era uma professora não indígena. Ali na aldeia Cachoeirinha por conta da língua não fiz tanta amizade. Novamente meu pai foi transferido.

Fomos morar na Aldeia Jaguapiru, município de Dourados, MS, território do povo Guarani Caiowá e Terena. Ali fiz muitas amizades, também estudei na escola da aldeia, tinha professores indígenas e não indígenas, acho que já um pouco crescido já prestava atenção nas explicações dos professores, terminei a terceira série, e novamente e definitivamente meu pai foi transferido para a recém criada Aldeia Tereré, município de Sidrolândia, MS, no ano de 1985.

A minha avó Flaviana Alcântara Figueiredo e meu avô João Batista Figueiredo, até por influencia que eles tinha na época com o Coordenador da FUANAI e Campo 
Grande, MS, pediram que meu pai fosse transferido pra recém criada Aldeia Tereré, e que estava precisando de um enfermeiro.

Nesse período tinha meus dez anos de idade, fui matriculado em uma escola na cidade muito conhecida, Escola Municipal "Olinda Brito de Souza", nessa escola me parece que eu já estava bem situado no mundo escolar, lembro que na quarta serie, a escola promoveu um concurso de tabuada e, eu ganhei ficando em primeiro lugar, o meu irmão foi campeão de embaixadinha, ele tava na terceira série.

Pois bem, em meio a esses entre lugares fui construindo minha identidade, a maior parte da minha infância foi no meio do povo guarani, vivi guarani, brincava guarani, dançava guarani, cantava guarani, porém ao dormir a minha mãe me contava histórias Terena.

Parece que não íamos mais mudar, era definitivo viver na aldeia Tereré em Sidrolândia, MS. Meu pai servidor da FUNAI realizava os casamentos dos indígenas, já não fazia só a função de enfermeiro, pois era atribuído também o papel do chefe de posto, registrar nascimento e casamento de índio no livro de registro da FUNAI, cresci vivenciando isso, de vez em quando meu pai pedia para que eu o ajudasse, cresci lendo e decorando o Estatuto do Índio (Lei 6001, de 19 de dezembro de 1973). Isso pra mim era magnífico, nem sabia o que significava. Mas estava ali ajudando meu pai, ajudando meu tio Cacique da Aldeia Tereré João Figueiredo filho, popular Capitão Santo.

Ajudar meu tio, Capitão Santo com os trabalhos da Aldeia e meu pai Joaquim Loureiro Figueiredo Neto com os trabalhos que não era só a função de enfermagem, mas também outras atribuições foram importante para aminha formação e entendimento sobre a questão indígena, foi ali o inicio do meu envolvimento com a questão indígena, a construção da minha identidade, defensor da causa indígena, mesmo sem saber o que estava acontecendo, mesmo sem ter uma leitura de sociedade, eu já estava ali trabalhando, fazendo documentos, tudo era eu, aí não parei mais.

Na aldeia Tereré em Sidrolândia lembro que gostava muito de jogar futebol, fiz muita amizade por conta do futebol, saía pra jogar fora representando a cidade, sonhei em ser jogador de futebol, e por ai vai. Terminei o fundamental na escola estadual "Sidrônio Antunes de Andrade".

Também estudava música, eu era contratado pela Banda Musical de Sidrolândia, era percussionista, apresentamos e ganhamos títulos estaduais e nacionais em concursos de bandas musicais. Aos dezoitos anos de idade sai da banda musical, tirei a carteira de trabalho e fui trabalhar na construção do frigorífico, indústria de alimento 
"Agro Eliane". Ao terminar a construção do frigorífico, passei a trabalhar na linha de produção. Trabalhei um ano e meio, e sai, acho que indignado com a situação, meu chefe de setor tinha apenas a terceira série do fundamental, a indústria estava recém começando, e as oportunidades que iam surgindo sempre era dos não indígenas que iam preenchendo os cargos.

Ainda sem concluir o ensino médio, já com vinte anos de idade Deus me abençoou com o casamento. Nesse período parei de estudar, pois tinha que trabalhar, eu tinha uma família pra sustentar e não tinha nenhuma formação. Meu filho nasceu e, eu desempregado, fui trabalhar na usina Santa Olinda uma indústria de açúcar e álcool, em Sidrolândia, pois ali trabalhei três meses, não foram nada fáceis, entre febre e dores no corpo, mãos calejadas, estava findando a safra no mês de dezembro. Ai a reflexão, não vou aguentar, o salário não vai dar conta da manutenção da família, para completar morava na cidade pagando aluguel.

Após a reflexão estava decidido voltar a estudar, pois estava convencido de que através dos estudos poderia ter melhores oportunidades. Não lembro como, mas sei que meu nome estava inscrito na segunda turma do Magistério Indígena. Fui estudar na escola "Pe. Félix Zavattaro", Curso de Formação e Habilitação de professores de 10 a 4 은 Série do 1 o grau para o contexto indígena.

Concluí o curso de 2o grau na escola "Pe. Félix Zavattaro", Curso de Formação e Habilitação de professores de 1으 a 4은 Série do1으 Grau para o contexto indígena no ano de 1999. Para mim uma oportunidade única, o convívio e experiência com outras pessoas de comunidades Terena e outros grupos étnicos que compõe o estado de Mato Grosso do Sul e Mato Grosso, contribuiu muito para minha compreensão da diversidade linguística, cultural e de ideias. Porém não atuei na educação.

Nesse tempo ainda não existia a escola Cacique João Batista Figueiredo, e sim um projeto "Curso de Ensino de Língua Terena" através da Portaria no 003/11/95, a primeira professora que atuou nesse projeto foi a Professora Maria de Lourdes a principio como professora de língua Terena, natural da Aldeia Cachoeirinha município de Miranda. Minha primeira experiência como professor foi no ano de 1997 e 1998. Depois por questões internas nos próximos seis anos não atuei mais na sala de aula. Fui trabalhar em outros espaços, manutenção de aviários entre outros serviços, sem carteira assinada.

Em 2002, trabalhei na indústria de confecção de vestimenta como mecânico e eletricista em Sidrolândia, em 2003 prestei vestibular pra área de administração 
na Universidade Estadual de Mato Grosso do Sul (UEMS), em 2004 era acadêmico de administração, em 2005 e 2006 voltei pra sala de aula como professor na escola extensão Cacique João Batista Figueiredo.

No mesmo ano, prestei vestibular para o curo de Normal Superior, porque no próximo ano não poderia mais voltar pra sala de aula, os professores teriam que estar cursando o curso superior na área de educação. Porém, mesmo iniciando o Normal Superior, já não tinha mais a vaga para minha lotação na escola, por motivo de priorizar outros professores, fiquei de fora.

Não perdi a esperança, fui para aldeia Barreirinho, Terra Buriti, município de Dois Irmãos do Buriti, pois esta comunidade estava recentemente criando e construindo a Escola "Silvério Rodrigues Mamedes", me recebeu de braços abertos. Ali trabalhei por quatro anos, e ao mesmo tempo cursava o Normal Superior, foi uma grande experiência, desenvolvi bons trabalhos na sala de aula, também era visto como uma liderança. Conclui o Normal Superior em 2010.

Em 2011 fui convidado para trabalhar na Secretaria de Assuntos Indígenas do município de Dois Irmãos do Buriti. Uma das primeiras secretarias municipal já criada no Brasil. Pais de alunos não queriam que eu deixasse a sala de aula, era uma resposta e resultado do bom trabalho que desenvolvi na aldeia Barreirinho. Neste momento a Terra Indígena Buriti dos municípios de Sidrolândia e Dois Irmãos do Buriti já estavam em processo de retomada das terras tradicionais.

No mesmo ano fiz inscrição como aluno especial no Curso de Pós Graduação Mestrado em História da Universidade Federal da Grande Dourados (UFGD), conclui a disciplina de Antropologia do Colonialismo. Curso que me orientava mais ainda sobre a história dos povos indígenas. A luz da militância indígena ficava cada vez mais acesa.

Ainda no final do segundo semestre de 2011, fui convidado pela comunidade da Aldeia Tereré Terra Buriti, município de Sidrolândia para assumir o cargo de Cacique. Pois neste momento estava preste a encarar um conflito interno, me sentia preparado para tal embate, não só com os conflitos internos, mas, com os problemas externos e principalmente político ideológico.

Foi um ano de embate, sem nenhum prestigio político em Sidrolândia, não me contrataram, era mais um professor formado fora da sala de aula por conta dos interesses políticos naquele momento.

A comunidade sempre me dando força, pois estavam confiando na minha visão social e política, precisávamos estar bem politicamente para que pudéssemos 
dar os próximos passos. Em 2013 deixamos de ser oposição e passamos ser situação. Fui contratado para trabalhar na assessoria do gabinete do Prefeito em Sidrolândia, colocamos os projetos em prática, principalmente na área de educação e território.

Em 2015 conclui o curso de Especialização "Cultura e Historia dos Povos Indígenas", do programa de Pós Graduação da Universidade Federal de Campo Grande (UFMS) iniciando também o mestrado no Programa de Pós Graduação em Educação (PPGE) da Universidade Católica Dom Bosco (UCDB) em Campo Grande (MS) na Linha de Pesquisa III- Diversidade Cultural e Educação Indígena.

Pois bem os estudos me proporcionaram coisas boas, mas também problemas, digo coisas boas no sentido de ter oportunidades para o mercado do trabalho, trabalhei como professor por um curto período, trabalhei na gestão da política publica municipal em Dois Irmão do Buriti e Sidrolândia. Digo problema porque é no campo político que está as tensões de conflitos ideológicos acontecem. Os estudos me fizeram ver a sociedade, e vi que os povos indígenas foram vítimas da sociedade colonizadora, no começo tinha essa visão fragmentada que ao longo dos tempos e através dos movimentos e estudos foram aumentando a minha visão de sociedade, principalmente sobre a história dos povos indígenas. Nesse momento também consolidava cada vez mais á construção da minha identidade enquanto militante do movimento indígena. E aqui estou eu.

\section{Sobre o autor:}

Maioque Rodrigues Figueiredo: Coordenador na Escola municipal Indígena Cacique João Batista Figueiredo, na Aldeia Tereré Terra Indígena Buriti, município de Sidrolândia (MS) e mestrando no PPGE/UCDB. E-mail: maioque.indi@hotmail.com

\section{Recebido em 9 de fevereiro de 2017}

Aprovado para publicação em 13 de março 2017 
